\title{
Informe geológico resumido: Area San Pedro de Atacama
}

Francisco Pimentel B. ${ }^{1}$

\section{Generalidad geológica de la zona de San Pedro de Atacama}

El objetivo de este trabajo es entregar en forma esquematizada la información geológica que existe sobre la zona, a fin de que pueda ser utilizada como apoyo en trabajos extradisciplinarios y, en general, para difundir el conocimiento geológico entre las personas que se interesan por la zona.

La información se ha obtenido de las siguientes fuentes:

- Fundamentos de Geología de Chile, 1950, J. Bruggen.

- Cuadrángulo Tulor, 1963, R. Digman.

- Cuadrángulo San Pedro de Atacama, 1965, R. Digman.

- Geología del Salar de Atacama, 1969, Moraga y colaboradores.

- Geología de superficie, subsuperficie y geoquímica del Salar de Atacama, 1972, Díaz y colaboradores.

- Información verbal de Gustavo Le Paige.

- Observaciones de terreno.

Morfología. El Salar de Atacama es una depresión tectónica de $3500 \mathrm{~km}^{2}$ de superficie que funciona como una cuenca de recepción de aguas superficiales y subterráneas, así como de escombros provenientes de las cadenas de cerros que la circundan: por el este: el "plateau riolítico" o conjunto de rocas volcánicas estratificadas expuestas en una gran extensión areal y en forma de un plano inclinado hacia el oeste. Sobre este plano inclinado emergen aparatos volcánicos modernos.

Por el oeste: La Cordillera de Domeyko.

Por el norte: Lo limita una extensión de material volcánico derramado desde el este.

1 Geólogo egresado de la Universidad de Chile, Santiago, CHILE.
Por el sur: Afloramientos de rocas volcánicas provenientes del este y rocas de distinto tipo.

Morfológicamente el Salar de Atacama tiene una expresión llana con lagunas en su interior.

Su borde o ribera está demarcado por el contacto de la costra salina (del Salar), con las unidades elásticas (arena y/o grava), pertenecientes a acumulaciones de material suelto proveniente del relieve inmediatamente superior.

Estos depósitos tienen una pendiente hacia el oeste y están disecadas por quebradas que evacuan las aguas cordilleranas. En el sector de Zapar se evidencian algunas fallas de desplome de poca extensión. Este depósito sobreyace parcialmente a las ignimbritas que afloran inmediatamente al este.

Las ignimbritas (liparitas) o "plateau riolítico" tienen una gran distribución areal, aflorando en el sector noroeste del Salar y desde el noreste hasta el sureste, del mismo modo de un plano inclinado que guarda una pendiente de $20^{\circ}$ al oeste. Tienen una red de fracturas de orientación noroeste y oeste-sureste, sobre la cual se desarrolla el drenaje con marcada preferencia al noroeste. En su límite oeste (en el sector del Salar) las ignimbritas presentan un escarpe, producto de la erosión eólica, con desprendimiento de bloques; el efecto erosivo es más intenso en la desembocadura de las quebradas del drenaje. El escarpe en este sector no es producto de falla.

Sobre el plano inclinado de las ignimbritas emergen aparatos volcánicos modernos, algunos activos, de formas agudas, que tienen una fuerte expresión sobre el paisaje, sobresaliendo entre ellos el Licancabur (6065 m.snm). En los bordes, bases y alrededores de los volcanes se observan las coladas del material expelido por ellos y depositado sobre las ignimbritas.

Por el nor-noroeste del Salar aflora un conjunto de capas de arcillolita, limolita y sal (sal común y yeso), que se hallan muy plegadas y que conforman 


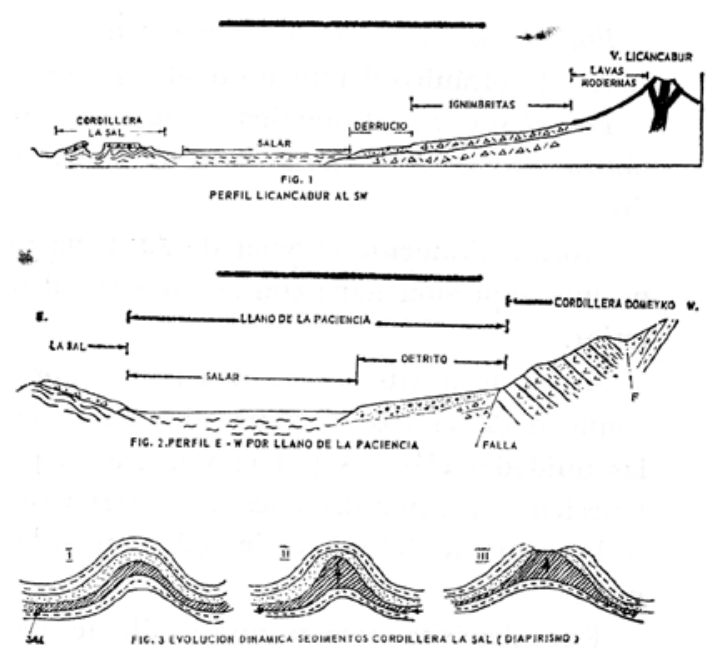

Figura 1. Perfil desde el Licancabur hacia el suroeste.

la Cordillera de la Sal. Debido al material que la compone, muy susceptible de ser disgregado y arrastrado por las aguas, lluvias y el viento, se han modelado formas extrañas que han dado el nombre de Valle de la Luna al lugar.

Hacia el oeste del Salar se alza la Cordillera de Domeyko, de orientación nor-noroeste, y se extiende desde el nor-noreste de San Pedro hasta la cuadra de Taltal. Su punto más alto se halla en el cerro Quimal (4400 m.snm). El borde oriental de esta cordillera es más abrupto que el occidental, debido a una falla de carácter regional que la limita. Al pie de estos cerros, por el flanco oriental, se ha depositado el detrito o piedemont que alcanza hasta el Salar.

En el sector norte de Vilama y Valle Chico aflora la ignimbrita, que ha sido afectada por fallas y fracturas que han determinado la formación de colinas muy elongadas, de orientación noreste, entre las cuales se evacua el agua superficial.

\section{Estratigrafía}

Las rocas que predominan en la región son las de origen volcánico (cuaternarias y terciarias). Las con mayor distribución areal, entre las volcánicas, son las ignimbritas, le siguen en extensión los depósitos salinos (Salar) y los depósitos clásticos poco consolidados (piedemont y eólicos). La posición de estos estratos es subhorizontal y de poca inclinación. Las rocas más antiguas (pz) afloran a través de ventanas tectónicas.
Rocas sedimentarias paleozoicas

Este tipo de rocas está expuesto a través de ventanas tectónicas entre la ignimbrita que circunda por el oeste al Salar, y afloran en dos localidades: a $14 \mathrm{~km}$ al sureste de Toconao y en el cerro Cas al sureste de Socaire; allí han sido definidas dos formaciones:

- Formación Chinchilla: Expuesta en un cerro isla del mismo nombre, su litología consiste en cuarcitas finamente estratificadas, con intercalaciones de conglomerados y escasas intercalaciones de mica-esquistos.

- Formación Cas: Aflora en el cerro del mismo nombre, ubicado al oeste-suroeste, su litología corresponde a rocas del tipo queratofírico.

Rocas sedimentarias jurásicas

Las rocas asignadas a esta edad afloran entre Toconao y Tilomonte, en los cerros que sobresalen al plano inclinado de la ignimbrita. En la localidad de Peine ha sido definida la:

- Formación Peine: Su litología corresponde a rocas sedimentarias depositadas en ambiente litoral (margas, lutitas, calizas y areniscas) y continental (areniscas, ignimbritas) y a rocas volcánicas andesíticas.

Rocas sedimentarias cretásicas

Las rocas sedimentarias cretásicas afloran en la Cordillera de Domeyko, y en la quebrada de Purilactis ha sido definida la Formación Purilactis, que es un paquete sedimentario de $3500 \mathrm{~m}$ de espesor. Su litología corresponde a rocas clásticas continentales, intercalaciones volcánicas y sedimentos litorales; contiene algunos estratos de sal (halita) y yeso. Esta formación está intensamente plegada observándose en algunos lugares inclinaciones de hasta $70^{\circ}$.

\section{Rocas sedimentarias terciarias}

Estas rocas son las que tienen mayor distribución areal en la zona, la litología de las rocas asignadas a esta edad corresponden a sedimentos clásticos de origen continental y rocas de origen volcánico, entre las cuales sobresalen por su espesor y extensión las ignimbritas (liparitas). En el área circundante al Salar se han definido cuatro formaciones: 
- Formación San Pedro: Asignada al Terciario Inferior que comprende un espesor de $2000 \mathrm{~m}$ de sedimentos de origen continental (lutitas, limolitas, areniscas, conglomerado fino, halita -sal común- y yeso). Los estratos de esta formación se hallan fuertemente plegados, estructurando un anticlinorio o conjunto de pliegues convexo hacia la superficie, estrecho y cuyo eje se orienta al nor-noreste. Esta formación es la que compone la llamada Cordillera de la Sal.

- Formación Tambores: Asignada al Terciario Medio, sobreyace a la Formación San Pedro. Su litología consiste en paraconglomerados y areniscas poco consolidadas, depositados en el área comprendida entre el borde oeste del Salar y el flanco oriental de la Cordillera de Domeyko.

- Formación Riolítica (Liparítica): Consiste en flujos de cenizas, material piroclástico y vidrio, todos soldados en estratos potentes (de gran espesor), con intercalaciones de material clástico (arena, guijarros) y material lahárico (barros originados por la depositación de productos volcánicos ardientes sobre hielo). Su extensión areal comprende desde el norte de la provincia de Tarapacá (formaciones Oxaya y Altos de Pica) hasta el sur de la provincia de Antofagasta (Formación Riolítica). Esta formación ha sido afectada por una tectónica de bloques, flexuras y sobreescurrimientos.

- Formación El Tambo: Aflora en el sector sureste del Salar. Litológicamente compuesta por calizas y sedimentos clásticos, esta formación está afectada por la misma tectónica de bloques que la riolítica.

\section{Depósitos sedimentarios cuaternarios}

Las rocas o acumulaciones asignadas a esta edad han sido agrupadas en dos formaciones y tres unidades o depósitos:

- Formación Vilama: Comprende estratos de diatomitas, cenizas y turbita, depósitos de piedemont y terrazas aluviales. Esta formación aflora en el sector de Vilama y ha sido observada en la quebrada del río Puripica. En el sector norte de Vilama la formación está afectada por plegamientos y fallas de escurrimiento de orientación noreste.
- Formación Salar de Atacama: Corresponde a los depósitos de evaporitas que rellenan el centro de la cuenca del Salar.

- Depósitos aluviales: Esta unidad incluye materiales de piedemont, depósitos aluviales, fluviales y coluviales, producidos y desarrollados por crecidas ocasionales, pero que arrastran gran cantidad de material.

- Depósitos volcánicos: Constituidos por andesitas, piedra pómez y cenizas volcánicas que sobreyacen a la Formación Riolítica.

- Depósitos eólicos: Este depósito fue originado por los vientos predominantes de la zona noroeste, y que producen el desprendimiento, acarreo y depositación de material fino en diferentes lugares de la región.

\section{Rocas intrusivas}

En el área han sido detectadas tres tipos de roca intrusiva, correspondientes a tres diferentes edades:

- Paleozoico: Consiste en un granito que aflora en el cerro Lila, ubicado al sureste del Salar.

- Cretásico Medio: Granodiorita y rocas asociadas, ubicadas en los cerros al noreste de Peine, en el cerro Lila y probablemente en la Cordillera de Domeyko, han sido asignadas a esta edad.

- Terciario Medio: Las rocas intrusivas asignadas a esta edad consisten en unos pórfidos dacíticos, que afloran en la localidad de Peine.

Principales estructuras expuestas

Las estructuras de mayor envergadura en esta área son:

- Falla del borde oeste del Salar, que delimita por el flanco oriental la Cordillera de Domeyko.

- Sinclinorio o conjunto de pliegues que conforman la Cordillera de la Sal, cuyo eje principal está orientado al nor-noreste.

- Juego de fallas normales y/o rumbo en el sector norte de San Pedro (Vilama). 
- Monoclinal formado por las ignimbritas con inclinación al oeste.

\section{Historia geológica}

El Paleozoico no está documentado lo suficiente, debido a la escasez de afloramientos, como para reconstituir los eventos en ese período acaecidos.

Durante el Jurásico, en la región existía un ambiente litoral, representado ahora por los sedimentos litorales y continentales (Formación Peine). Las relaciones de contacto entre el Jurásico y rocas más antiguas, así como con las del Cretácico, no están definidas debido a la escasez de afloramientos y lo distante de éstos.

La Formación Purilactis documenta el Cretácico; en su base o piso contiene un conglomerado formado por rodados calizos que contienen fósiles asignados al Jurásico. Esto es debido a una orogénesis o movimiento que alteró la posición de todas las rocas anteriores al Jurásico inclusive. La orogénesis produjo un alzamiento general, dejando las rocas expuestas a la erosión, y los rodados producidos por ésta, sirvieron de base o piso para el relleno posterior.

La Formación Purilactis en su desarrollo tiene un ambiente netamente continental. Al término del Cretácico o comienzos del Terciario se produjo la última orogénesis principal que afectó también a la Formación Purilactis.

Posteriormente, durante el Terciario, se depositaron materiales detríticos en una cuenca (clásticos), invadiéndola en forma de flujo. Este flujo estaba saturado de sales; las primeras de éstas en precipitarse fueron los carbonatos, que se depositaron en los bordes de la cuenca (cerro Mármol). La halita parece provenir de las formaciones mesozoicas.

Con el peso de los sedimentos la cuenca se asentó, produciendo el movimiento de los sedimentos hacia su centro; éstos, al estar saturados, actuaron plásticamente plegándose. La sal intercalada entre los sedimentos se desplazó hacia centros de menor presión entre los pliegues, formándose gruesos volúmenes que migraron a la superficie, plegando y rompiendo los estratos superiores (pliegue diapiro).

Sobre la Formación San Pedro, y en el borde oriental de la Cordillera de Domeyko, se depositó material clástico de origen continental, que es el producto del ataque de los agentes erosivos sobre el nuevo relieve.
Durante el Terciario Superior se produjeron abundantes efusiones volcánicas, a partir de fisuras de probable orientación norte-sur. El material (ignimbrita) fue depositado rellenando la topografía preexistente, construyendo un paisaje llano, del que sobresalen los relieves más elevados. Las intercalaciones de material lahárico y clástico, que son contemporáneas con estos derrames, se originan por la depositación de proyectiles y material volcánico fino ardiente sobre hielo, y por el arrastre y depositación de limos $\mathrm{y}$ arenas por otros agentes erosivos.

A fines del Terciario existió una laguna en la cuenca y en la cual se empiezan a depositar algunos sedimentos propios de este ambiente (Formación El Tambo).

A comienzos del Cuaternario continúa la depositación de sedimentos propios del ambiente lagunar (Formación Vilama), hoy documentada por los paquetes de diatomitas, arcilla, turba, etc., ubicada en el área de Conde Duque, Quitor, quebradas de los ríos Puripica y Puritama; en estas quebradas el paquete sedimentario se halla "colgado" de los flancos de las mismas, revelando un cambio de nivel de base, $o$ sea un descenso del nivel donde desembocaban tales ríos. Las terrazas que se incluyen en esta formación son posteriores al depósito de las sedimentitas. Este cambio de nivel va asociado a un movimiento de la corteza regional y/o cambios climáticos, los cuales determinaron la eliminación del ambiente lagunar por una disminución de la tributación fluvial.

Este cambio de régimen hizo evolucionar la actividad y ambiente de la cuenca, transformándose paulatinamente en un salar y depositándose gruesas capas de evaporitas y otros sedimentos (Formación San Pedro).

El resto de los depósitos (eólicos, de piedemont, etc.) corresponden a la destrucción de transporte y acumulación de materiales detríticos, por los agentes erosivos (temperatura, gravedad, viento, lluvia, etc.), que actúan en condiciones y lugares diferentes, produciéndose la diferenciación de los depósitos.

\section{Geología económica}

\section{Minería metálica}

La actividad en este rubro es nula en este momento, a pesar de que existen algunas posibilidades de reiniciarlas. Hay lugares donde se han realizado algunas faenas, las cuales se han paralizado por diferentes circunstancias. 
- Minas de San Bartolo (Cu): Se hallan en la localidad del mismo nombre, a $25 \mathrm{~km}$ de San Pedro, por la quebrada del río San Pedro. Geológicamente ubicadas en un nivel de areniscas de la Formación San Pedro; estas areniscas han sido correlacionadas por Brüggen con las de Corocoro (Bolivia), las cuales contienen yacimientos importantes de cobre. Estas ruinas se encuentran actualmente anegadas y ofrecen muchas dificultades para su drenaje.

- Mina NN: Ubicada frente a Sequitor, en el flanco oriental de la Cordillera de la Sal, consiste en una falla mineralizada por óxidos (atacamita, malaquita). Esta mina corresponde a un yacimiento secundario, es decir los minerales allí depositados que han sido transportados por aguas subterráneas desde su yacimiento originario o primario, ubicado aguas arriba.

- Picados de Peine: En esta localidad existen pequeñas vetas de cobre y oro, asociadas al pórfido dacítico de edad terciaria.

- Yacimiento El Laco: Aunque distante del área englobada en este trabajo, se ha incluido en este capítulo por su importancia e influencia potencial en la zona. Este yacimiento contiene un gran volumen de mineral de hierro de alta ley y corresponde a una efusión constituida casi exclusivamente por magnetita y hematita.

\section{Minería no metálica}

Aunque en esta actividad no hay producción, a excepción de pequeñas explotaciones de halita $(\mathrm{Na}$ Cl) y puzolana (sapolio), la realidad es que existen posibilidades para el beneficio de no-metálicos.

\section{Litio y potasio}

En las evaporitas y salmueras del Salar existen grandes concentraciones, relativas a este tipo de elementos, que ofrecen excelentes perspectivas para su explotación; no así para su mineralurgia, que exige alta tecnología, un volumen considerable de energía y otros recursos. El origen de estos dos elementos está en la lixiviación, por parte de las aguas meteóricas, de las ignimbritas y andesitas del oriente del Salar.

Azufre

Existen yacimientos de cierta importancia en el sector, tales como Purico, Putana, etc. pero debido a la inaccesibilidad, inclemencia climática, e inconveniencias de precio, hacen improbable su explotación por el momento.

\section{Puzolana}

Este tipo de ceniza volcánica, muy rica en sílice $\left(\mathrm{SiO}_{2}\right)$, puede ser utilizado como abrasivo fino, agregado para la producción de cemento, etc. Es relativamente abundante en la zona; aflora en otros lugares, en el contacto oriental de la Formación San Pedro con los depósitos de piedemont.

Halita (sal común)

En la Cordillera de la Sal existen núcleos de pliegues diapiros, con importantes volúmenes de este material y con leyes bastante altas (97\%).

Piedra pómez y obsidianas

Materiales de uso industrial y ornamental (obsidiana) abundan en los alrededores de los volcanes.

Ignimbrita (liparita)

Roca de uso en la construcción como elemento básico y como piedra ornamental. Por su alto contenido de sílice, puede tener algunos usos industriales.

San Pedro de Atacama, enero de 1975. 